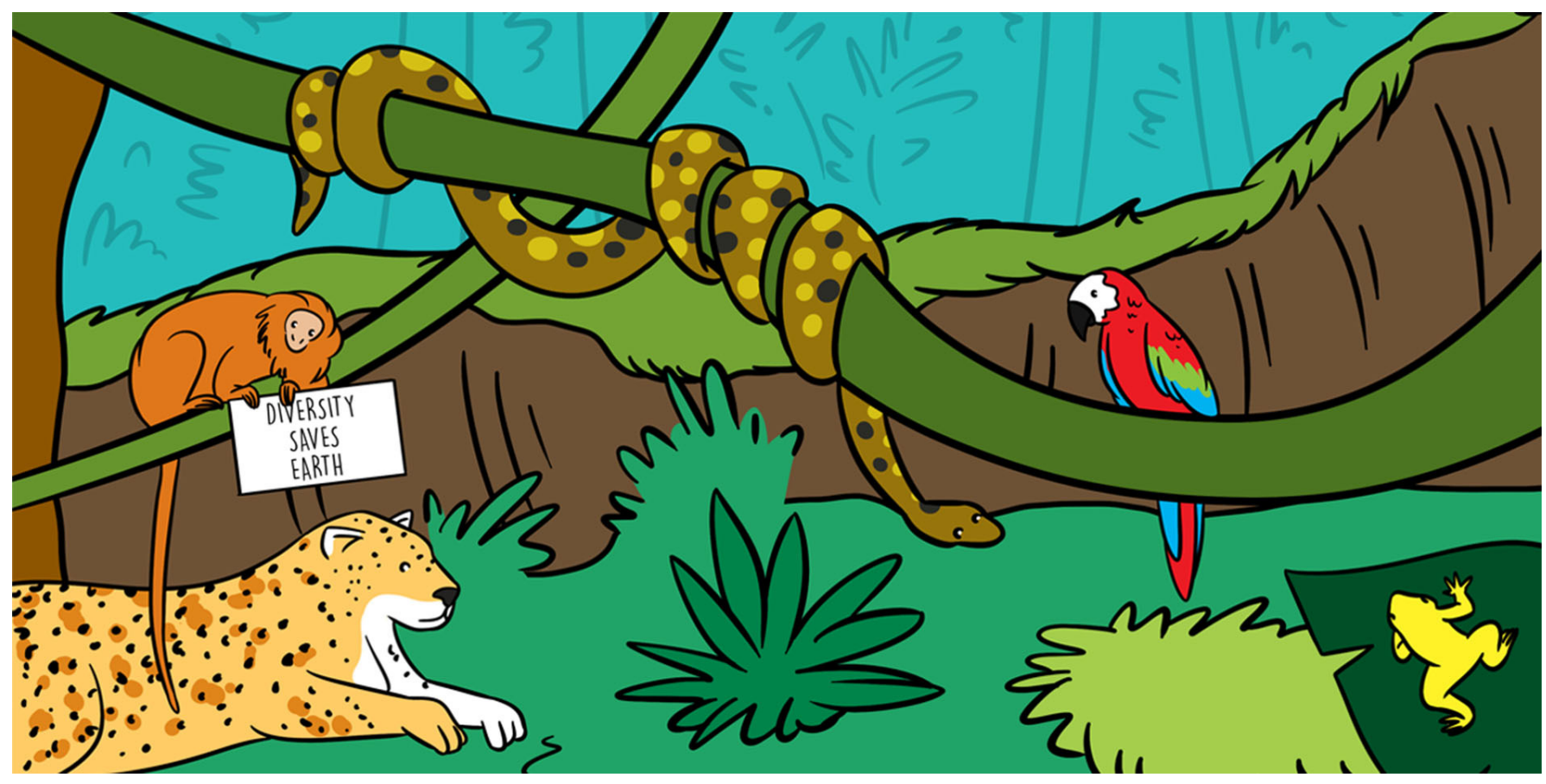

\title{
CAN ANIMAL BIODIVERSITY HELP THE CLIMATE?
}

\author{
Mar Sobral ${ }^{1 *}$, Celia Arias-Vaquerizo ${ }^{2}$, Kirsten M. Silvius ${ }^{3,4}$ and José M. V. Fragoso ${ }^{5,6}$ \\ ${ }^{1}$ Area of Ecology, Department of Functional Biology, Universidade de Santiago de Compostela, Santiago de Compostela, Spain \\ ${ }^{2}$ Department of Edaphology and Agricultural Chemistry, Universidade de Santiago de Compostela, Santiago de Compostela, \\ Spain \\ ${ }^{3}$ United States Forest Service-International Programs, Washington, DC, United States \\ ${ }^{4}$ Department of Forest Resources and Environmental Conservation, Virginia Tech University, Blacksburg, VA, United States \\ ${ }^{5}$ Departamento de Zoologia, IB Universidade de Brasília, Brasilia, Brazil \\ ${ }^{6}$ Institute for Biodiversity Science \& Sustainability, California Academy of Sciences, San Francisco, CA, United States
}

\section{YOUNG REVIEWER:}

THEODOR AGE: 13
This article shows that the number of different kinds of mammals and their interactions affect the way carbon, an element essential for life, moves between plants, animals, and the environment in the Amazon. It was already known that plant biodiversity affects this cycling of carbon, and some scientists had suggested this relationship might be true for animals, too. Mammals and their interactions increase the amount of carbon stored in soils and trees. When carbon is stored, this helps to slow down climate change, because that carbon is removed from the atmosphere. But animal populations worldwide are decreasing. We should consider that conservation of mammals will increase the carbon storage in soils and trees, and therefore help us fight climate change. 


\section{CARBON CYCLE}

The movement of carbon between atmosphere, soil and biosphere is the carbon cycle.

\section{PHOTOSYNTHESIS}

Process by which plants grow using sunlight to capture Carbon from the atmosphere.

\section{BIODIVERSITY}

The number of species present in a site.

\section{CARBON MOVES THROUGH LIVING AND NON-LIVING THINGS VIA THE CARBON CYCLE}

All living things contain an important element called carbon. But that is not the only place you will find carbon. Carbon is present in the environment, too-in the water, in the soil, and in the earth's atmosphere. Carbon constantly cycles between living things and the environment, in a process called the carbon cycle.

Plants are the key biological players in the carbon cycle because they capture carbon from the atmosphere. Through a process called photosynthesis, plants absorb carbon dioxide $\left(\mathrm{CO}_{2}\right)$ from the atmosphere and use light energy from the sun to make carbon-containing molecules called carbohydrates, along with the oxygen we breathe. Every year, plants transform atmospheric $\mathrm{CO}_{2}$ into about 100 billion tons of carbohydrates. We commonly recognize these carbohydrates as roots, stems, and leaves. This movement of carbon between earth's atmosphere and the plants is just part of the carbon cycle. When plants die, the carbon in their roots, stems, and leaves passes into the soil. In the soil, some carbon from dead plants may be changed by soil microorganisms to become part of the soil, while some returns to the atmosphere. Whenever more carbon is captured-taken up into living organisms and soil-then less carbon is available to enter the atmosphere.

You may have heard that $\mathrm{CO}_{2}$ is one of the gases in earth's atmosphere that contributes to climate change and the warming of our planet. In the carbon cycle prior to the Industrial Revolution, only two factors regulated the concentration of $\mathrm{CO}_{2}$ in the atmosphere: photosynthesis and geological phenomena like volcanoes, etc. With the onset of the industrial age, a new factor, human activity, began to disrupt the natural carbon cycle. Activities, such as burning wood and fossil fuels added carbon to the atmosphere and changed the climate.

When carbon is removed from the atmosphere and incorporated into living things or the soil, this may help to slow climate change.

\section{BIODIVERSITY IS IMPORTANT}

The tropical forests have the greatest plant biodiversity on the planet. Biodiversity is the variety of living beings in a place. Trees in the tropical forests are fundamental to the carbon cycle because they capture carbon and regulate the climate. But a forest is not made up of just plants. Many other forest organisms play an important role in the carbon cycle. For instance, the biodiversity of mammals influences the carbon cycle in the Amazon [1]. 
Biodiversity is important because each species plays a role in nature. When many different species make up an ecosystem, a higher number of roles or functions are developed and thus the ecosystem is healthier. Biodiverse ecosystems might provide important services to humanity. One such service has to do with carbon accumulation. Biodiversity may reduce the concentration of carbon in the atmosphere, and that reduction may help to decrease climate change.

As we have already explained, plants capture carbon from the atmosphere and accumulate it as carbohydrates in their leaves, stalks, and roots. Scientists measure carbon accumulation as the mass of carbon contained in the body. We know that plant biodiversity increases the amount of carbon captured [2]. And we know that plants and animals interact with each other. Based on this information, we wanted to find out whether mammals, as they relate to plants, also play a role in the carbon cycle [1]. Mammals may interact with plants in several ways. For instance, they eat plant fruits, leaves, and flowers. Also, animals disperse plant seeds.

Our hypothesis was that the biodiversity of mammals present in an environment will increase the amount of carbon that accumulates in the soil. To test this hypothesis, we observed nature directly, using the traditional ecological knowledge of several indigenous (local) tribes who live in the tropical forests of Guyana.

\section{WHAT DID WE DO}

Our hypothesis was difficult to test with direct observations of animals that live in a challenging, real-world system, such as the Amazon. Massive amounts of data were needed, which required the participation of 355 Makushi, Wapishana, and Wai-Wai indigenous people from Guyana. These people collected animal data for the study, and their knowledge about local natural systems was essential to the quantity and quality of the data. These local people had accumulated expert knowledge of the relationships between plants and animals over hundreds of years of direct contact with the environment.

For 3 years and across 18,500 square miles, these indigenous people conducted more than 10,000 surveys. Their work identified 218,000 individual mammals belonging to 48 species. They recorded more than 43,000 feeding events and more than one million samples of animal poop. Additionally, soil carbon concentrations and tree sizes were measured at hundreds of sites.

\section{WHAT DID WE FIND}

Our results showed that the diversity of mammals, in addition to the diversity of trees, affects the carbon cycle in the Amazon (Figure 1). 
Figure 1

Relationship between the biodiversity of mammals and the percent of carbon in soils. As the number of different types of mammals increased (from left to right on the graph), the percent of carbon in the soil also increased (from bottom to top of the graph). Each dot represents a transect in the Amazonian forest.

\section{Figure 2}

Interactions between organisms are part of the carbon cycle. Arrows represent the movement of carbon between the atmosphere, the plants, the animals, and the soil. In the soil, some carbon from dead plants and animals may be changed by soil microorganisms to become part of the soil, while some returns to the atmosphere. Through the photosynthesis plants absorb carbon from the atmosphere and grow leaves flowers and fruits. Animals eat plants or other animals later they poop and die and carbon cycles back into the soil. The movement of carbon between atmosphere, soil and biosphere is the carbon cycle.

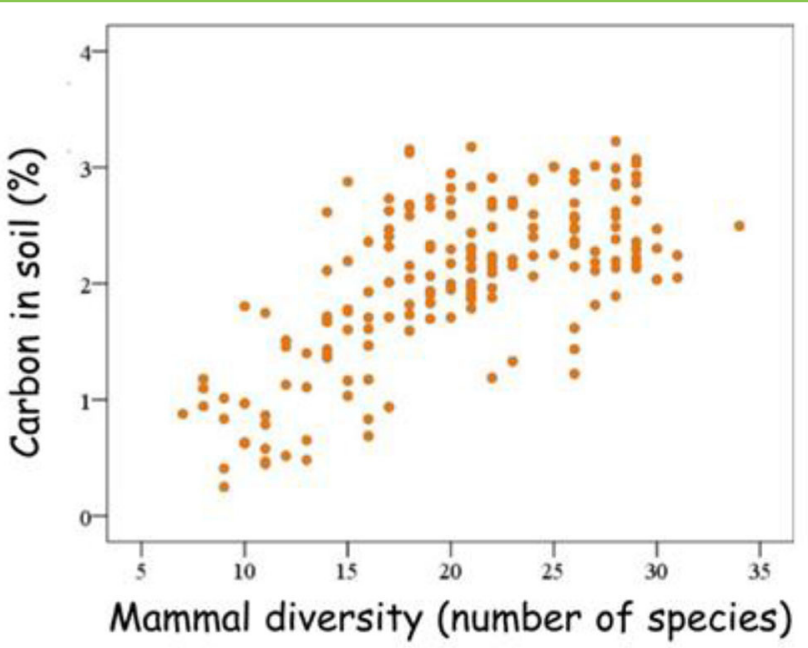

Figure 1

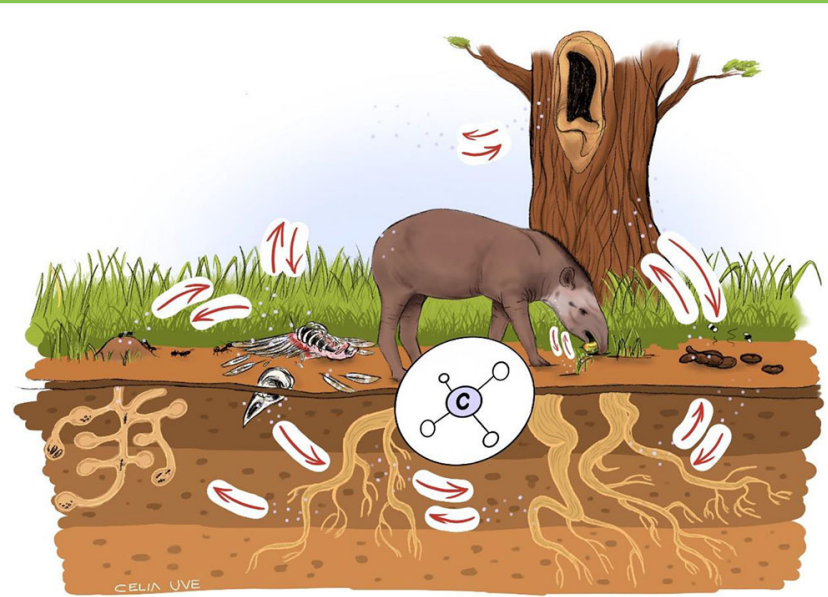

Figure 2

More species mean different types of interactions, such as animals eating plants etc. and therefore more carbon moving from living beings to the soil (Figure 2). As we predicted in our hypothesis, we found that the number of mammal species is related to the concentration of carbon in the soil in the Amazon (Figure 1). The number of mammal species is also related to the amount of carbon stored in tree biomass. We also found relationships between the number of tree species, the amount of carbon in soil, and tree biomass. For carbon concentration in soils, we found the magnitude of the effect of mammal diversity was equivalent to the magnitude of the effect of tree diversity.

\section{WHY IS THIS RESEARCH IMPORTANT?}

This research is important because it provides evidence that every species plays a role in nature, which means that losing species can be harmful to natural processes. This idea has already been accepted 
for the plant world [2], and it seems logical that relationships between plants and animals would be important for the carbon cycle, too.

Although we still have much more to learn about the relationships between animals, plants, and the carbon cycle, it is clear from our work that animal loss caused by humans may be a climate problem, and conservation of animal biodiversity may be a climate solution. While our study focused specifically on mammals and on Guyana, we believe the findings might also be true for different creatures, such as reptiles, amphibians, birds, and invertebrates, and in different types of forests. These differences need to be tested.

This study is important in three different ways. First, it improves the understanding of the world we live in and the natural world with which we have evolved. Second, this study highlights the importance of the knowledge of indigenous people about their natural systems. Their knowledge was pivotal to finding that mammal diversity may contribute to a cleaner sky. Third, this work shows that actions to protect animals and our environment may also help humans. Mammal diversity should be one of the factors considered when policies are made that aim to reduce the amount of $\mathrm{CO}_{2}$ in our atmosphere.

\section{ACKNOWLEDGMENTS}

We thank all people who participated in this research: Ted K. Raab, Anthony Cummings, Kye Epps, Han Overman, and F. B. Oliveira among others. Especially we thank the Makushi, Wapishana, and Wai-Wai technicians whose fieldwork and local knowledge made this research possible. Thanks also to Leslie Willoughby for improving the text. We thank the National Science Foundation (NSF; Grant BE/CNH 05 08094), the Gordon and Betty Moore Foundation, and Stanford University for financial and administrative support.

\section{ORIGINAL SOURCE ARTICLE}

Sobral, M., Silvius, K. M., Overman, H., Oliveira, L. F. B., Raab, T. K., and Fragoso, J. M. V. 2017. Mammal diversity influences the carbon cycle through trophic interactions in the Amazon. Nat. Ecol. Evol. 1:1670-6. doi: 10.1038/s41559-017-0334-0

\section{REFERENCES}

1. Sobral, M., Silvius, K. M., Overman, H., Oliveira, L. F. B., Raab, T. K., and Fragoso, J. M. V. 2017. Mammal diversity influences the carbon cycle through trophic interactions in the Amazon. Nat. Ecol. Evol. 1:1670-6. doi: 10.1038/s41559017-0334-0 
2. Poorter, L., Van Der Sande, M. T., Thompson, J., Arets, E. J. M. M., Alarcón, A., Álvarez-Sánchez, J., et al. 2015. Diversity enhances carbon storage in tropical forests. Glob. Ecol. Biogeogr. 24:1314-28. doi: 10.1111/geb.12364

SUBMITTED: 19 February 2020; ACCEPTED: 18 August 2020;

PUBLISHED ONLINE: 29 September 2020.

EDITED BY: Frederique Carcaillet, Université de Montpellier, France

CITATION: Sobral M, Arias-Vaquerizo C, Silvius KM and Fragoso JMV (2020) Can Animal Biodiversity Help the Climate? Front. Young Minds 8:536333. doi: 10.3389/ frym.2020.536333

CONFLICT OF INTEREST: The authors declare that the research was conducted in the absence of any commercial or financial relationships that could be construed as a potential conflict of interest.

COPYRIGHT (c) 2020 Sobral, Arias-Vaquerizo, Silvius and Fragoso. This is an open-access article distributed under the terms of the Creative Commons Attribution License (CC BY). The use, distribution or reproduction in other forums is permitted, provided the original author(s) and the copyright owner(s) are credited and that the original publication in this journal is cited, in accordance with accepted academic practice. No use, distribution or reproduction is permitted which does not comply with these terms.

\section{YOUNG REVIEWER}

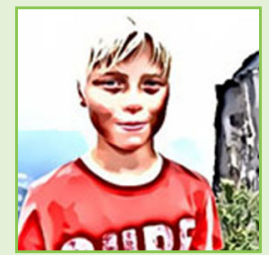

\section{THEODOR, AGE: 13}

My name is Theodor, and I live in a city near the coast in Central Norway. I love doing outdoor activities and sports, like cross-country skiing, running, hiking, and camping in the mountains. My favorite wildlife species is the cheetah. I also like reading books about how the natural world works.
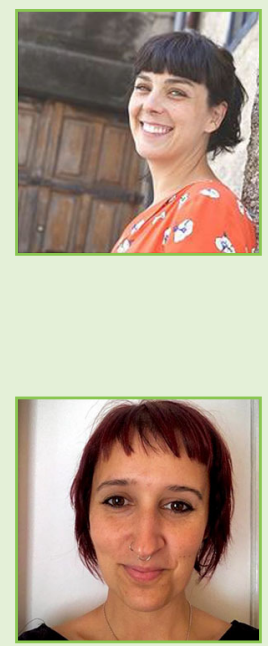

\section{AUTHORS}

\section{MAR SOBRAL}

Mar Sobral loves nature and kids. She is a scientist in ecology and a mommy. She researches and teaches at the University of Santiago de Compostela in Spain. She previously lived and worked in Romania, Germany, US, and France. She specializes in the relationships between animal and plants investigating what does this mean for evolution and for the functioning on the planet. Other passions for her are dogs, coffee, yoga, and dancing! *sobral.bernal.mar@gmail.com

\section{CELIA ARIAS-VAQUERIZO}

Celia Arias-Vaquerizo is a Ph.D. student, illustrator, and a nature lover. She has always been fascinated by ancient animals and how they lived in the past. Her research is about how domesticated animals lived in the past and how humans took care of them. She believes that knowledge is for everybody and she is therefore 


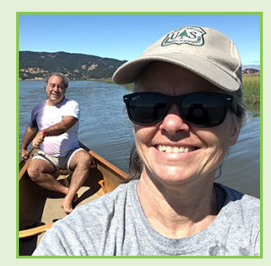

passionate about telling stories through drawings, especially environmental and cultural curiosities.

\section{KIRSTEN M. SILVIUS}

Kirsten Mariana Silvius is a research associate at Virginia Tech and a technical advisor to the US Forest Service's Brazil Program. Born and raised in Venezuela, Kirsten completed her higher education in the United States. She received a B.A. degree in Biology and Romance Languages from Bowdoin College, Maine, and both M.S. and Ph.D. degrees from the Zoology Department at the University of Florida. Trained as a terrestrial ecologist, her research has focused both on plant-animal interactions and on wildlife use and management by local and indigenous peoples. She has studied a diversity of animal species in Venezuela and Brazil, including agoutis, parrots, peccaries, beetles, and parasitic wasps. Her most recent work is in support of sustainable harvest and sale of Brazil nuts, açai fruits, and the giant Arapaima fish by traditional and indigenous communities in the Brazilian Amazon. Among her favorite hobbies are hiking, camping, and canoeing with her husband Joe Fragoso.

\section{JOSÉ M. V. FRAGOSO}

José Manuel Vieira Fragoso is a university professor and research scientist. He enjoys learning about the secret lives of plants and animals, especially in tropical areas. He also enjoys long walks and canoeing in natural areas, especially in remote regions of the Amazon and Canada. 